\title{
A CORUÑA, "CIUDAD DE VERANO" NA DÉCADA DE 1930. DOUS PROXECTOS HOTELEIROS DE ANTONIO TENREIRO E PEREGRÍN ESTELLÉS ${ }^{1}$
}

Data recepción: 2013/06/11

Data aceptación: 2013/10/03

Contacto autor: juandavid.diaz@usc.es
Juan David Díaz López

Universidade de Santiago de Compostela

\section{RESUMO}

Fronte ao panorama expansivo que presenta a industria hoteleira da Coruña nos prósperos anos de 1920, os 30 parecen baleiros de iniciativas novas. Pero a realidade é que a comezos da nova década os arquitectos Antonio Tenreiro e Peregrín Estellés abordan dous proxectos turísticos de promoción pública que rivalizan en ambición cos mellores exemplos anteriores. Relegados non obstante ao papel, ilustran dúas formas de concibir o hotel de vacacións, tipo ligado cunha parte significativa da historia hoteleira de Galicia.

Palabras chave: arquitectura, hotel, turismo, Galicia, Tenreiro-Estellés

\section{ABSTRACT}

Unlike the outlook of expansion that Corunna's hotel industry presents during the thriving 1920s, the 1930s seem empty of new enterprises. But in fact, at the beginning of this decade, architects Antonio Tenreiro \& Peregrin Estellés took charge of two state-sponsored tourist projects that compete in ambition with the highest previous examples. Although they were not built, these projects illustrate two ways of conceiving the resort hotel, a type linked to a significant part of the Galician hotel history.

Keywords: architecture, hotel, tourism, Galicia, Tenreiro-Estellés

Como xa tivemos oportunidade de sinalar nun traballo anterior, a creación de hoteis na Coruña experimenta un importante impulso durante a década de $1920^{2}$. Durante esta etapa tan marcada polo desenvolvemento económico e a cultura da opulencia -que incide de maneira especial en Estados Unidos e nas principais urbes de occidente-, A Coruña aposta pola industria do turismo e pola conversión da cidade nun referente para o veraneo no norte de España á altura de cidades como San Sebastián ou Santander. Alentados pola visión dunha "ciudad de verano", en expresión que acuña a publicidade da época, empresarios particulares e poderes públicos tratan de promover algunhas arquitecturas hoteleiras realmente ambiciosas, como a do frustrado Gran Casino-Hotel (1920), deseño de Rafael González Villar cuxas 190 habitacións previstas foron apenas compensadas pola aper- tura do Atlantic (1923) e polas ampliacións do Palace (1925) e do Ferrocarrilana (1927). Pero máis alá dunha arquitectura hoteleira que non acaba de definirse, é destacada a multiplicación nestes anos de establecementos modestos que se fan chamar hoteis, especialmente nos últimos anos da década, nun contexto en que a creación do Patronato Nacional do Turismo (1928) e as exposicións universais de Sevilla e Barcelona (1929) exercen de estímulo para a industria do aloxamento española. Dispares na súa categoría, luxos e servizos, os hoteis coruñeses dos "felices anos 20" van inzando os longos listados de hospedaxes impresos nas cada vez máis frecuentes guías turísticas, formando un conxunto inseparable co gran reclamo que supoñen para a cidade as festas de agosto ${ }^{3}$.

Fronte a este panorama expansivo que puidemos describir con máis ou menos detalle, a 
década de 1930 aparece baleira de iniciativas hoteleiras novas, e soamente damos constancia da continuación das actividades dos hoteis antigos, que na súa meirande parte sobreviven á Guerra Civil e se internan na posguerra. É entón, nos anos 40, cando nacen o Finisterre (1947) e o Embajador (1948), os dous primeiros hoteis coruñeses que consideramos establecidos en arquitecturas ad hoc, ou especificamente concibidas para o uso hoteleiro, dado que todos os exemplos previos operan con máis ou menos reformas en edificios orixinalmente destinados a un uso diferente, case sempre residencial ${ }^{4}$. Dende a perspectiva das tipoloxías arquitectónicas que guía a nosa investigación, isto representa un importante desfase cronolóxico en relación ao resto de Europa ou Estados Unidos, onde os primeiros edificios hoteleiros aparecen a finais do século XVIII para xeneralizarse ao longo do XIX. Vale que é tardía a chegada do hotel ao ámbito español, onde o termo "fonda" perdura bastante tempo para designar a máis alta categoría hospedeira; pero aínda así, mesmo para unha Galicia na que o concepto non prende ata o último cuarto de século e que dá os primeiros froitos arquitectónicos na década de $1880^{5}$, a demora ata a ditadura de Franco resulta un tanto anómala.

Por esta razón, pensamos que pode ser interesante incorporar ao noso relato dous proxectos adicionais pertencentes aos primeiros anos $30 \mathrm{e}$ ámbolos dous asinados polo arquitecto coruñés Antonio Tenreiro Rodríguez (1893-1972), xunto co seu socio Peregrín Estellés (1891-1981). Trátase de dúas obras de notables dimensións que non foron realizadas, pero que -como xa sucedera co Gran Casino-Hotel unha década antes- demostran que a dotación de infraestruturas turísticas para A Coruña, nomeadamente dun gran hotel, era anos antes do Finisterre unha preocupación que congregaba intereses públicos e privados. $\mathrm{O}$ primeiro proxecto é o dun Hotel de Turismo, tal como se denomina na documentación, e constituiría un gran edificio exento previsto para o núcleo urbano; en cambio, o segundo corresponde coa urbanización dunha extensa zona rústica inmediata á praia de Santa Cristina, xa no veciño concello de Oleiros, pero en clara subordinación á estratexia de promoción da cidade herculina como destino vacacional. $\mathrm{O}$ interese municipal nestas dúas iniciativas aparece documentado en varias noticias de prensa, das que nos consta a primeira en maio de 1930: refírense como melloras próximas a acometer pola alcaldía, pero supeditadas ao respaldo do Patronato Nacional do Turismo, organismo implicado no seu financiamento e supervisor dos planos ${ }^{6}$.

\section{Un gran Hotel de Turismo}

O soporte do Patronato ás propostas coruñesas de ampliación da infraestrutura turística da cidade enmárcase no crecente esforzo estatal para a promoción dunha industria que xa revela un gran potencial económico. Iniciada en 1905 coa Comisión Nacional e continuada en 1911 coa Comisaría Regia del Turismo y Cultura Artística, a organización administrativa do turismo en España intérnase nos anos 20 co espírito proteccionista e intervencionista que domina a política económica destes anos e lastrada pola escaseza de recursos asignados. Pero a novidade, coa creación por Real Decreto de 25 de abril de 1928 do Patronato Nacional del Turismo, é a determinación de actuar sobre ámbitos directamente relacionados co turismo ata entón desatendidos, como a propaganda, as comunicacións ou os aloxamentos. Neste sentido, considérase prioritario ampliar e mellorar a infraestrutura hoteleira, para o que se establece entre outras medidas o Servicio de Crédito Hotelero, destinado a facilitar a construción de hoteis por parte da iniciativa privada, en tanto que a rede de Paradores créase para proporcionar unha oferta hoteleira pública e de calidade?.

Porén, os resultados do Patronato na súa curta traxectoria resultan escasos, polo menos no tocante á plasmación de proxectos hoteleiros en Galicia. Este organismo, entorpecido con múltiples cambios regulamentarios antes de convertela Franco na Dirección General de Turismo en $1939^{8}$, está a planear hoteis para Vigo, Santiago e A Coruña na altura de $1930^{\circ}$. Pero, un por un, os proxectos van quedando relegados: en Vigo, nin o esforzo do propietario do Hotel Continental para reedificar o establecemento con planos de Eduardo Lagarde nin o desexo de dotar a Samil dun hotel de praia acadan un apoio con resultados tanxibles ${ }^{10}$; tampouco Santiago, que acaba de ver inaugurado o seu Hotel Compostela coa 
bendición de representantes do Patronato, ve cumpridas todas as expectativas ata a apertura en 1954 do Hospital dos Reis Católicos como Parador de Turismo ${ }^{11}$; por último, como veremos, os propósitos para A Coruña tamén quedan no aire, e cando se reaviven nos anos 40 será xa con deseños arquitectónicos moi diferentes.

A primeira noticia que temos destes propósitos chega coa visita á Coruña do Conde de la Cimera, presidente do PNT, acompañado doutros cargos do organismo. O 14 de outubro de 1930 celebran unha reunión no Concello cos principais representantes da cidade, entre os que se contan o alcalde, o presidente da Deputación, o da Cámara de Comercio, o da Sociedade Coruñesa de Urbanización, así como delegados dos bancos Pastor e da Coruña. O obxectivo é tratar sobre a pertinencia e viabilidade dunhas obras que se están a propoñer como unha necesidade pública, especialmente no tocante á construción dun hotel de turismo, para o cal xa se presentan os planos asinados polo arquitecto municipal Antonio Tenreiro ${ }^{12}$. Neste momento, a súa localización está aínda por decidirse; pero algo máis tarde, en abril de 1931, o representante do PNT na Coruña, Luís Cornide, revela nunha entrevista cales son as principais zonas que se barallan: ben "a espaldas de la estatua de Carballo en los jardines de Méndez Núñez", nun área xa tenteada por proxectos hoteleiros; ou ben en Riazor, o que suporía unha primicia na valoración dunha praia á que aínda non prestara atención ningún hotel coruñés real ou proxectado ${ }^{13}$.

Malia o carácter preliminar da proposta, as mencionadas noticias de prensa apuntan a que a reunión de 1930 é satisfactoria e que existe a determinación por ambas partes de facer realidade o novo hotel. Como paso previo, déixase pendente en primeiro lugar aclarar o asunto da localización e, a continuación, constituír a sociedade que, co aval do Patronato, aportaría o diñeiro necesario para a construción e posta en funcionamento, cantidade estimada inicialmente en dous millóns e medio de pesetas. A creación dunha sociedade mercantil revela a magnitude do esforzo económico que nesta época requiren as apostas hoteleiras fortes, razón pola que o Atlantic e o Palace se converten nos anos 20 nas primeiras empresas en transcender a propiedade individual que rexera os hoteis coruñeses ata a década de $1910^{14}$. Tamén no tocante ao proxecto parece haber acordo cos representantes do PNT, que se amosan favorables á súa realización "salvo ligerísim[o]s detalles de colocación de alguna dependencia que en nada afectan a lo fundamental de la obra", exactitude que non deixa de ser curiosa tendo en conta que o seu destino está por determinar.

Así as cousas, compréndese o grado de abstracción do proxecto, concibido como unha

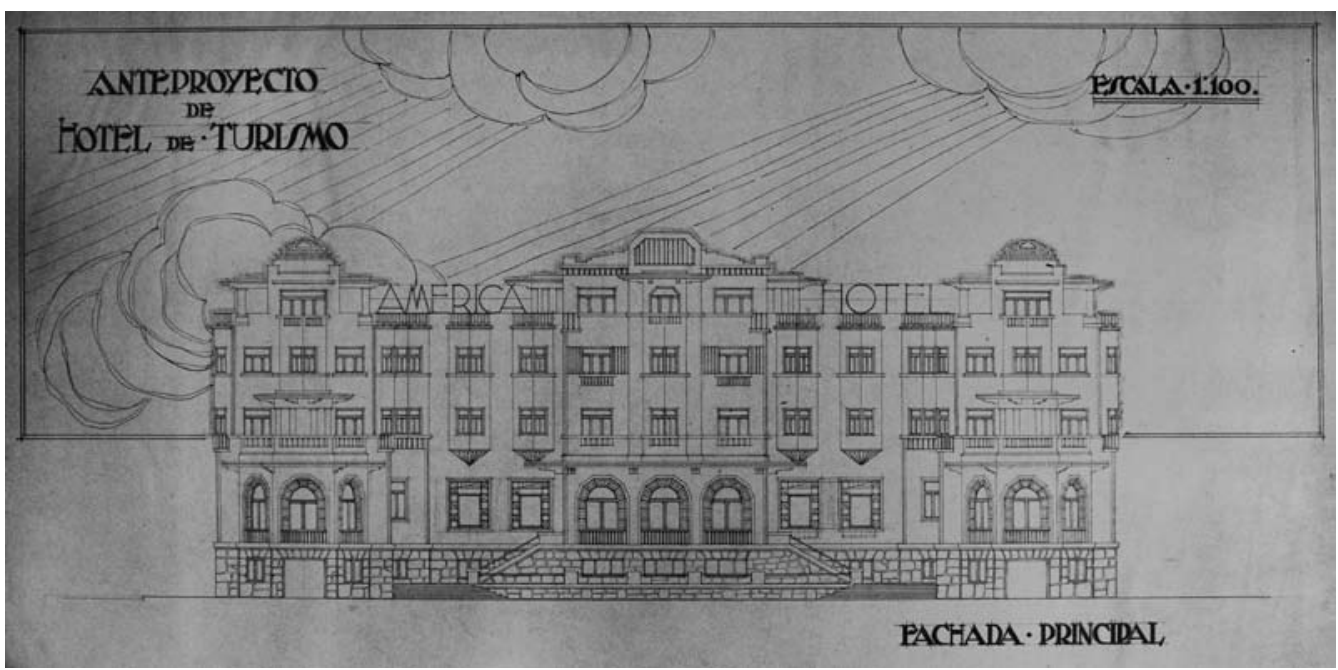

Fig. 1. Anteproxecto de Hotel de Turismo. Alzado principal. Sen data nin firma. Arquivo Municipal da Coruña (AMC) 
estrutura exenta e circunvalable, destinada a un soar de dimensións considerables e sen desniveis. Nove son os planos que se conservan no Arquivo Municipal da Coruña, deixando aparte unha carpeta de estudos e esbozos [figs. 1-9] ${ }^{15}$. Deses nove, catro titúlanse como "anteproyecto de hotel de turismo" e carecen de data e firma; mentres que os outros cinco, con pequenas variantes respecto aos primeiros, preséntanse co carácter máis definitivo de "proyecto", asinados na Coruña o 1 de marzo de 1931 por Antonio Tenreiro e polo seu socio Peregrín Estellés. Considerando a data dos planos que se pretenden definitivos -posterior á reunión-, pode pensarse que o "anteproyecto" andaría máis preto cronoloxicamente desa proposta preliminar que se amosa aos representantes do Patronato; ademais, pola similitude que gardan, o que non leva firma atribuímolo igualmente a Tenreiro e Estellés, sen excluír algunha participación do tamén arquitecto municipal Pedro Mariño ${ }^{16}$. Ámbolos dous deseños seguen unha pauta idéntica en planta, establecendo un amplo corpo principal ou corps de logis ao que se unen perpendicularmente outros dous laterais. Tanto o eixe de simetría do edificio -correspondente co centro da fachada principal- como cada un dos extremos dos corpos laterais reciben un tratamento enfático, ensanchándose para dar arranque a pavillóns diferenciados.

O resultado é un conxunto con planta en $H$, disposición que, evocando a tradición do

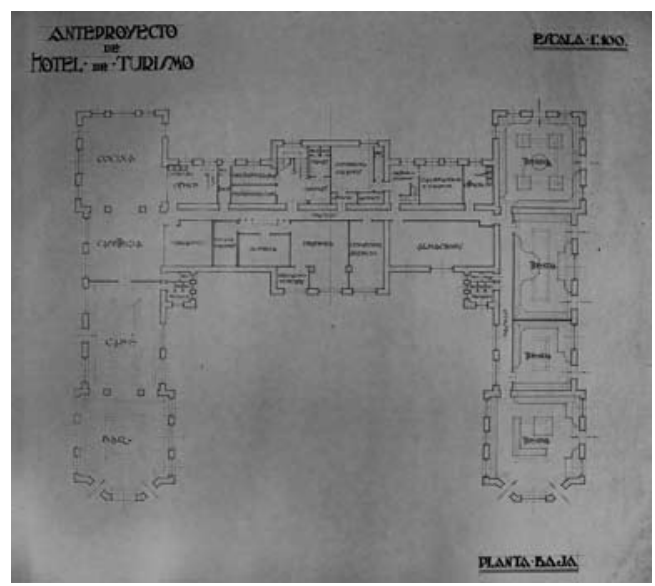

Fig. 2. Anteproxecto de Hotel de Turismo. Planta baixa. Sen data nin firma. AMC. château barroco, resulta axeitada para os hoteis de vacacións situados en escenarios naturais, libres das estreitezas polas que os hoteis urbanos son tipicamente compactos ${ }^{17}$. Neste sentido, o referente máis próximo atoparíase no Gran Hotel de Mondariz (1893-98), expoñente galego do grandilocuente estilo Segundo Imperio con proxecto de Jenaro de la Fuente Domínguez. Con independencia da diferente linguaxe ornamental, destaca a semellanza na composición en $\mathrm{H}$ de ambos edificios, unicamente matizada polo feito de que a proposta coruñesa sitúa a entrada principal na fachada de maior proxección dos

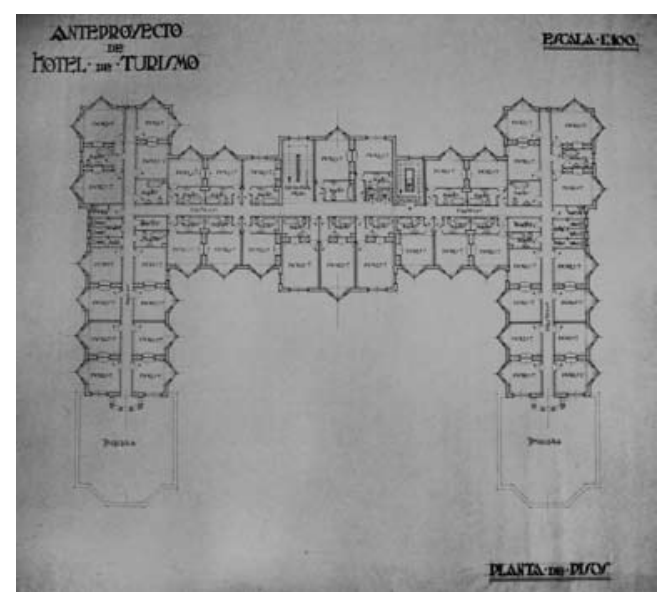

Fig. 3. Anteproxecto de Hotel de Turismo. Planta de pisos. Sen data nin firma. AMC

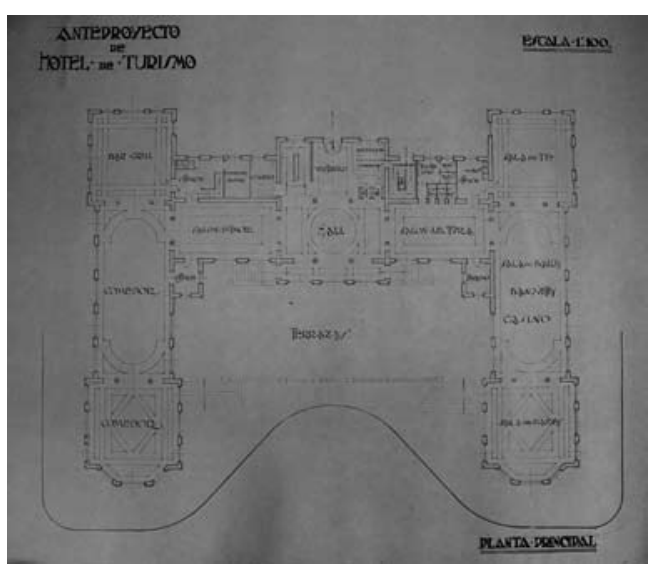

Fig. 4. Anteproxecto de Hotel de Turismo. Planta principal. Sen data nin firma. AMC 

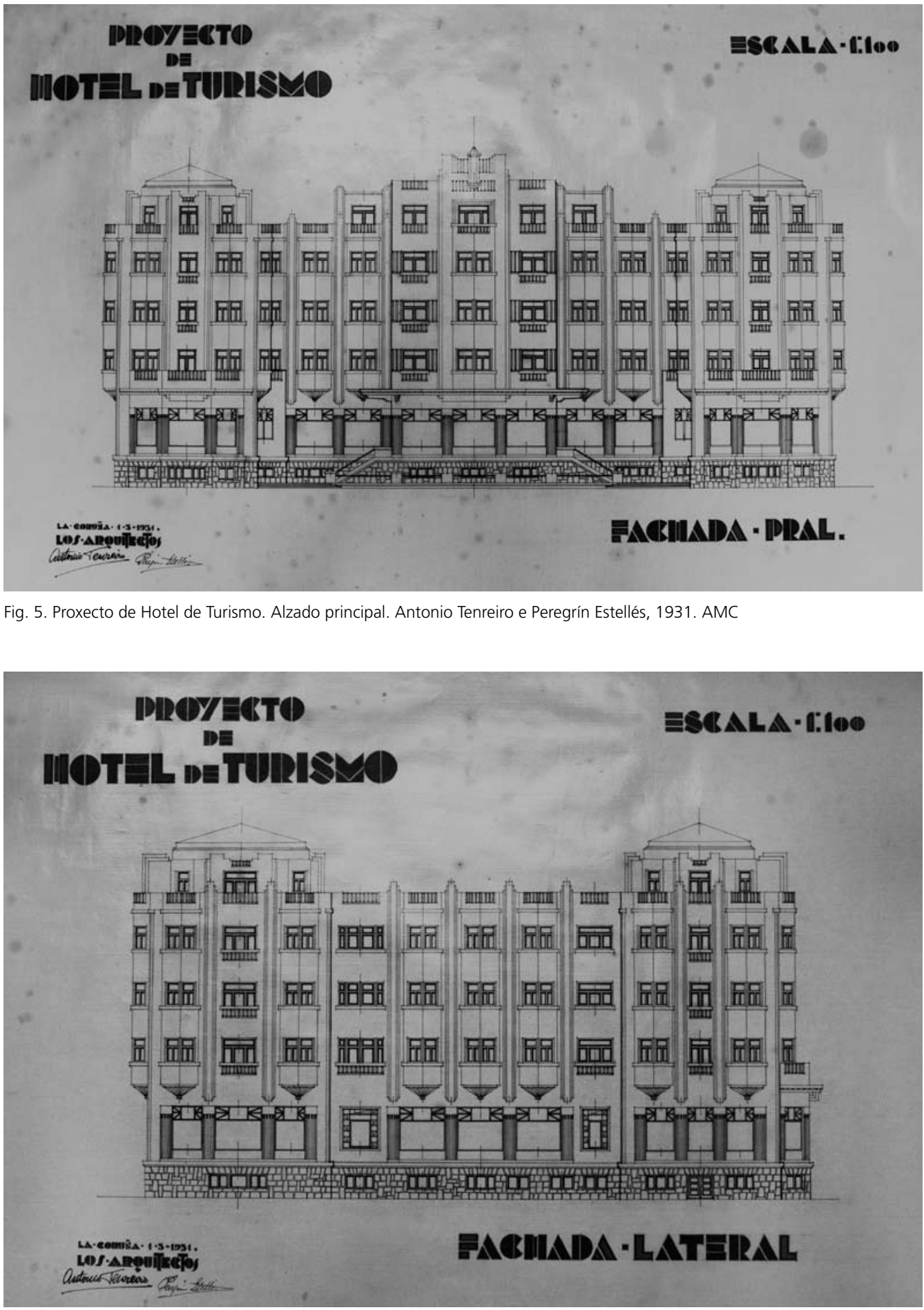

Fig. 6. Proxecto de Hotel de Turismo. Alzado lateral. Antonio Tenreiro e Peregrín Estellés, 1931. AMC 


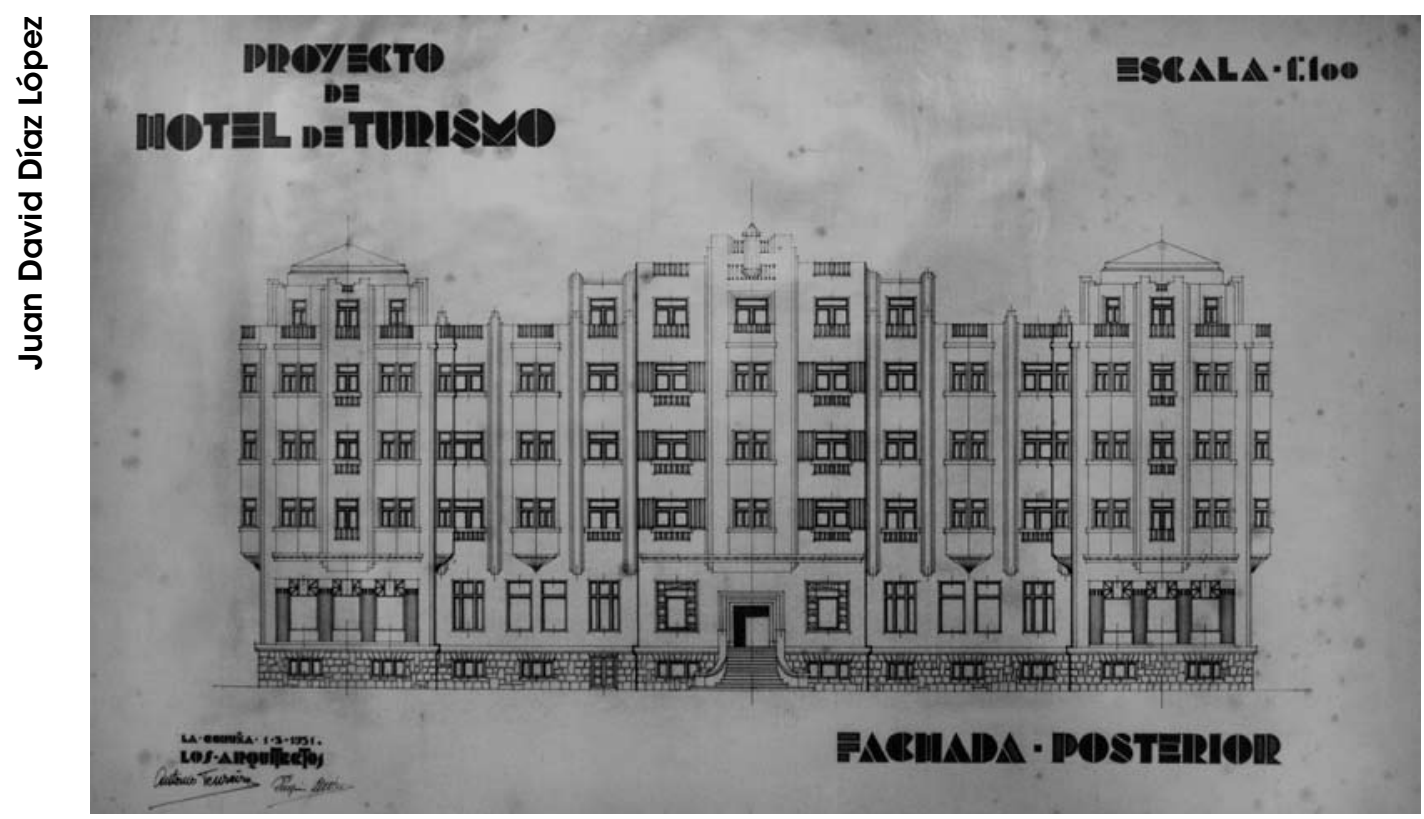

Fig. 7. Proxecto de Hotel de Turismo. Alzado posterior. Antonio Tenreiro e Peregrín Estellés, 1931. AMC

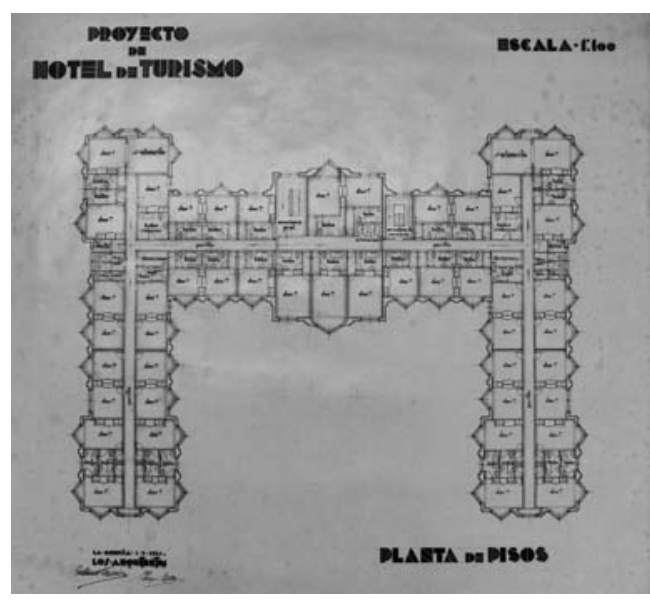

Fig. 8. Proxecto de Hotel de Turismo. Planta de pisos. Antonio Tenreiro e Peregrín Estellés, 1931. AMC

corpos laterais, no lado oposto que Mondariz, inscribíndoa así nun patio de honra á francesa que en todo caso ratifica o sabor palaciano do hotel. Para describir as funcións con que se dota e a súa organización, xustificando de paso a conexión dos nove planos cos artigos de prensa citados, parécenos oportuno comparar a información gráfica co testemuño publicado en El Orzán o 15 de outubro de 1930:

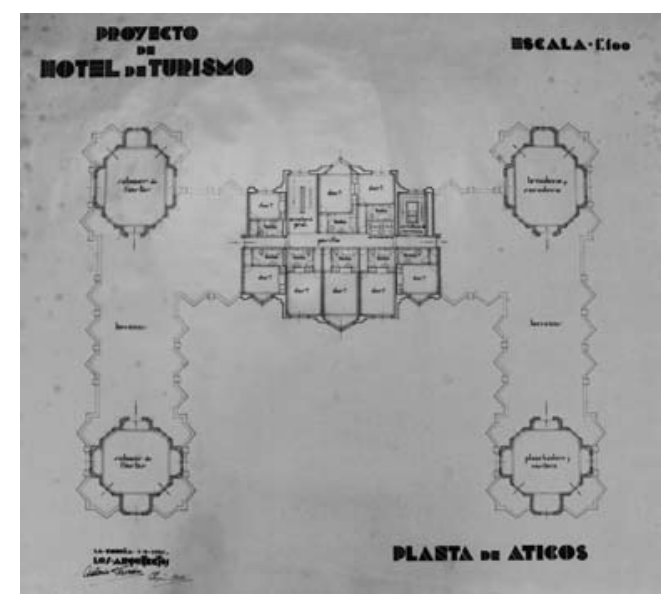

Fig. 9. Proxecto de Hotel de Turismo. Planta de áticos. Antonio Tenreiro e Peregrín Estellés, 1931. AMC.

El edificio constará de tres plantas. En la primera van el gran hall, un bar-café, dos comedores, un salón de te y la gran sala de fiestas, además de los salones de lectura y conversación, cabinas telefónicas, recepción, etc.

Las otras dos plantas estarán dedicadas exclusivamente a dormitorios.

Todas as pezas mencionadas para a primeira planta poden identificarse no plano do 
anteproxecto. En primeiro lugar, o hall, ampla estancia rectangular, sitúase no eixe de acceso e practicamente no que sería o corazón do edificio, exercendo de nó distribuidor principal pero tamén imprimindo dignidade a un espazo de vocación centralizada -cun círculo inscrito probablemente no pavimento- e limitado nos seus accesos por piares in antis. Este concepto de núcleo, receita usual para grandes edificios públicos, ten unha clara dimensión funcional en tanto pautadora dos fluxos de circulación, pero tamén está acorde coa tradición académica da composición simétrica e regular. Neste sentido, cabe lembrar que un dos máis emblemáticos fitos da historia do hotel, o Tremont House de Boston, debe parte da súa sona ao protagonismo con que dotou a súa rotonda central, enaltecida cunha cúpula sobre columnas, reforzando mediante refinamentos formais a facultade ordenadora do centro ${ }^{18}$.

O hall conecta con outro vestíbulo máis pequeno -inmediato á recepción e á entrada posterior-, co salón de lectura tamén referido e cun salón fumoir destinado ao consumo de tabaco. Todas estas pezas abarcan toda a lonxitude e boa parte da superficie do bloque principal do edificio, constituíndo o primeiro chanzo dos espazos públicos de uso cotián previstos para o hotel. Súmanse a eles, na entrada principal, unha terraza aberta ergueita sobre o zócolo, que acredita o éxito das que o Atlantic inaugurara na Coruña uns anos antes. Se o que diferencia ás antigas fondas da arquitectura propiamente hoteleira é o protagonismo que nesta cobran as estancias públicas e para a relación social, estamos diante do segundo proxecto, despois do Gran CasinoHotel, que reúne este requisito na cidade herculina, sendo o Atlantic un caso aparte polo seu inicial destino a pavillón de recreo sen servizo de hospedaxe ${ }^{19}$. Así, o resto da primeira planta do anteproxecto complétase exclusivamente con espazos públicos que enchen esas dúas alas abertas en ángulo recto respecto ao edificio central: trátase, como xa recolle a noticia de El Orzán, das imprescindibles salas de comedor, que ocupan todo un lateral antecedidas polo bar; mentres que no lado contrario se sitúa unha sala de té e os escenarios máis festivos, dispoñibles para bailes, banquetes ou como casino, un marco sen dúbida que desborda as funcións hospedeiras e que brindaría o encontro da burguesía tanto local como visitante.

Os dous pisos superiores, tal como afirma - redactor da noticia, estarían integramente destinados a albergar dormitorios coas súas correspondentes pezas de servizo, é dicir, baños ou váteres que poden ser de uso privado ou comunitario. Neste sentido, a observación dos planos revélanos unha evolución significativa na dotación dos equipos sanitarios, que se multiplican nas zonas residenciais ata o punto de que un número considerable de habitacións pasan a contar con cuarto de baño de uso exclusivo. Sirva como proba de que se está a producir un cambio de estándar o caso do Palace, nesta época principal hotel da Coruña xunto co Atlantic: en novembro de 1925 -apenas cinco anos antes-, os propietarios inician os trámites para engadirlle un novo piso no que prevén un só retrete e dous cuartos de baño para un total de 14 habitacións, moitas delas dobres ${ }^{20}$.

Para comunicar as diferentes plantas establécese no pavillón central, con arranque nun lateral do hall, unha escaleira de ida e volta carente de pretensións no tocante á súa sinxela estrutura; e mais outra escaleira de servizo de tres tramos irregulares que se sitúa acaroada ao mencionado pavillón. Por último, esta mesma zona alberga dous ascensores, máquinas que en 1930 distaban de ser unha novidade nos hoteis da Coruña, pero que ata entón só se incorporaran por medio da reforma de edificios preexistentes, sen partir dun proxecto arquitectónico orixinal como o que agora nos ocupa ${ }^{21}$.

Xunto á información coincidente que nos achegan as fontes gráficas e escritas, hai que sinalar algúns matices e diverxencias que non obstante consideramos insuficientes como para facernos pensar que remiten a proxectos distintos. En primeiro lugar, está o número de plantas, que segundo a peza de prensa son tres sen contar o soto, feito que se corrobora no alzado do anteproxecto, pero non así no proxecto de 1931, onde aparecen catro pisos mais o soto. En segundo lugar, está o número de habitacións, que o redactor cifra en 120, dato que contrasta $\cos 40$ dormitorios por cada piso do anteproxecto -o que faría un total de 80 - e cos 46 que ten cada un no proxecto -o que supoñendo tres 
pisos residenciais faría un total de 138-; todo isto sen contar con que existe un nivel de terrazas nas cubertas, con zonas festivas a modo de roof garden ${ }^{22}$, que inclué un pequeno pavillón con oito habitacións máis ${ }^{23}$. En terceiro lugar, está o número de váteres e de baños, sobre o que se di que as habitacións estarán "provistas todas de servicio de saneamiento", afirmación imprecisa que non pode corroborarse nos elementos representados no plano, mentres que se "noventa de ellas tendrán cuarto de baño y para las otras 30 se instalarán ocho baños más" as contas só se achegan ás que se deducen do proxecto de 1931. En derradeiro lugar, está a información sobre a denominada "planta baja" ou "sótano": resulta coincidente no relativo a unhas dependencias de servizo que adoitan ocupar esta posición ${ }^{24}$, como cociña, bodega, almacéns, caldeiras ou comedores do persoal; pero o proxecto de 1931 sitúa a lavandaría no ático ${ }^{25}$, ademais de que a descrición do xornal omite unha perruquería e, enchendo as alas laterais, un café-bar e catro tendas.

Para sintetizar os datos achegados polas diferentes fontes illando aqueles aspectos que inducen a confusión, parécenos útil presentar o seguinte cadro:

\begin{tabular}{|c|c|c|c|}
\hline & Anteproxecto [figs. 1-4] & Proxecto [figs. 5-9] & Fontes de prensa ${ }^{26}$ \\
\hline Denominación & $\begin{array}{l}\text { "Anteproyecto de Hotel de } \\
\text { Turismo" }\end{array}$ & $\begin{array}{l}\text { "Proyecto de Hotel de } \\
\text { Turismo" }\end{array}$ & $\begin{array}{l}\text { "Hotel de Turismo"; "Hotel"; } \\
\text { "Gran Hotel" }\end{array}$ \\
\hline Autoría & $\begin{array}{l}\text { Antonio Tenreiro e Peregrín Estellés } \\
\text { (atrib.), con posibles achegas de } \\
\text { Pedro Mariño }\end{array}$ & $\begin{array}{l}\text { Antonio Tenreiro e Peregrín } \\
\text { Estellés (con firma) }\end{array}$ & $\begin{array}{l}\text { Antonio Tenreiro (xunto a outros } \\
\text { dous técnicos) }\end{array}$ \\
\hline Data e lugar & Non constan & 1-||I-1931, A Coruña & $\begin{array}{l}\text { Non constan datos do plano; } \\
\text { noticias publicadas entre } 1930 \text { e } \\
1931\end{array}$ \\
\hline Localización & Non consta & Non consta & A Coruña (centro urbano) \\
\hline Pisos & $\begin{array}{l}\text { Soto }+1 \text { principal }+2 \text { residenciais } \\
+ \text { ático }\end{array}$ & $\begin{array}{l}\text { Soto }+1 \text { principal + } 3 \\
\text { residenciais + ático }\end{array}$ & $\begin{array}{l}\text { Soto }+1 \text { principal }+2 \text { residenciais } \\
\text { (omítese ático) }\end{array}$ \\
\hline Dormitorios & 80 (40 x2 pisos) & 138 (46 x3 pisos) & 120 (¿60 x2 pisos?) \\
\hline $\begin{array}{l}\text { Servizos de } \\
\text { hixiene }\end{array}$ & $\begin{array}{l}\text { Total contando } 2 \text { pisos: } 36 \text { baños } \\
\text { privados / } 8 \text { baños, } 4 \text { duchas e } 12 \\
\text { retretes comúns }\end{array}$ & $\begin{array}{l}\text { Total contando } 3 \text { pisos: } 84 \\
\text { baños privados / } 12 \text { baños, } 6 \\
\text { duchas e } 18 \text { retretes comúns }\end{array}$ & $\begin{array}{l}\text { Habitacións "provistas todas de } \\
\text { servicio de saneamiento". } 90 \text { baños } \\
\text { privados / } 8 \text { comúns }\end{array}$ \\
\hline $\begin{array}{l}\text { Dependencias } \\
\text { piso principal }\end{array}$ & $\begin{array}{l}\text { Hall; bar-grill; dous comedo- } \\
\text { res; cabinas de teléfono; salón } \\
\text { fumoir; de lectura; de té; de bailes, } \\
\text { banquetes e casino, entre outras } \\
\text { dependencias de servizo }\end{array}$ & Plano ausente & $\begin{array}{l}\text { "gran hall, un bar-café, dos } \\
\text { comedores, un salón de te y la } \\
\text { gran sala de fiestas, además de los } \\
\text { salones de lectura y conversación, } \\
\text { cabinas telefónicas, recepción, etc." }\end{array}$ \\
\hline $\begin{array}{l}\text { Dependencias } \\
\text { soto }\end{array}$ & $\begin{array}{l}\text { As de servizo: comedores do } \\
\text { persoal, cociña, bodega, despensa, } \\
\text { almacéns, frigorífico, carboeira, etc.; } \\
\text { pero non lavandaría. Ademais hai } \\
\text { unha perruquería e nas alas laterais } \\
\text { un café, un bar e catro tendas }\end{array}$ & Plano ausente & $\begin{array}{l}\text { "En el sótano irán la cocina y } \\
\text { repostería, despensa, bodega, } \\
\text { servicios higiénicos, tren de } \\
\text { lavado y planchado, refrigeradora, } \\
\text { calefacción, comedores para la } \\
\text { servidumbre, etc." }\end{array}$ \\
\hline $\begin{array}{l}\text { Dependencias } \\
\text { ático }\end{array}$ & $\begin{array}{l}\text { Plano ausente; pero aparece } \\
\text { representado no alzado }\end{array}$ & $\begin{array}{l}\text { Terrazas; } 8 \text { dormitorios con } \\
\text { baño; } 2 \text { pavillóns de festas e } \\
2 \text { para servizo de lavandaría, } \\
\text { tendal, ferro e costura }\end{array}$ & Non se menciona un ático \\
\hline
\end{tabular}


¿Ata que punto esta disparidade nos datos nos debe facer sospeitar que o proxecto exposto pola prensa e o representado polos planos son en realidade dous que nada teñen que ver? Na nosa opinión e coa información de que dispoñemos, a relación entre as referencias literarias e as gráficas é consistente. Dunha banda, consideramos que os elementos coincidentes son importantes, especialmente 1) pola repetida alusión a un "hotel de turismo" do que existen planos pero para o que non se decidiu localización concreta dentro da Coruña; 2) pola mención de Antonio Tenreiro como autor dun proxecto que vemos asinado na mesma cidade, onde ten o estudio, a praza de arquitecto municipal e que acolle de feito case toda a súa produción; e 3) pola axustada cronoloxía entre 1930 e 1931, que non se presta a encaixe co que sucede noutras cidades galegas - citábanse Vigo e Santiago como aspirantes a obras semellantes-, nin dá marxe para concibir simultaneamente na propia Coruña outra empresa hoteleira desta magnitude. Doutra banda, pensamos que os elementos diverxentes non abondan para dar por feita a independencia dos proxectos, especialmente cando as propias fontes gráficas presentan diferenzas numéricas significativas -nos pisos, dormitorios ou baños- sen anular por iso o núcleo común. Son diferenzas que ben poden atribuírse á imprecisión do xornalista nunha descrición que dista de ser unha memoria técnica, pero que derivan sobre todo de que estamos a falar dun deseño inacabado e en pleno proceso de transformación.

Este carácter provisional faise máis evidente na observación dos alzados, que coñecemos polos mesmos planos conservados no Arquivo coruñés. Un plano nos presenta a fachada principal do anteproxecto, carente como dixemos de firma e data, pero dotado singularmente dun rótulo sobre o coroamento co futurible nome do establecemento: "AMERICA HOTEL", unha denominación con ampla tradición que sen dúbida apela ao espírito cosmopolita e progresista da hotelaría, neste caso reflectido na idea do Novo Mundo e non menos na composición á inglesa pola que se pospón o termo "hotel" 27. Pola súa banda, os tres alzados do proxecto asinado en 1931 ofrécennos as fachadas principal, posterior e lateral do edificio.
Anteproxecto e proxecto son pois propostas moi parecidas: 1) ambas teñen unha fronte principal de 15 vans de anchura organizados en tramos triplos, 3 no pavillón central, 3 en cada tramo intermedio e 3 en cada pavillón extremo; 2) estruturan as fachadas conforme á tradición académica, superpoñendo un baseamento rústico, un corpo principal coa planta de honra resaltada e un ático sinalado nesa sorte de torres que emerxen graduándose sobre o coroamento; e 3) animan a parede con similar xogo de entrantes e saíntes, sobre todo ao dispoñer bandas verticais de bay-windows de planta triangular asentadas nun volume tetraédrico cun estriado a modo de vieira. Elementos diverxentes son, 1) como dixemos, o número de pisos -un menos no anteproxecto-; 2) a existencia dunha terraza sobre a planta principal nos extremos dos brazos do anteproxecto, elemento que se suprime no proxecto para ser ocupado por dormitorios, e velaquí a razón do aumento numérico por piso; e 3) a inclinación polo gusto déco, presente en ambas propostas, pero máis intenso no proxecto de 1931, onde Tenreiro aplica ao hotel todas as connotacións de modernidade e cosmopolitismo do estilo mediante recursos que xa ensaiara no edificio da Sociedade de Seguros Mutuos [fig. 10] ${ }^{28}$ : xunto á ondulación xeométrica que producen as bandas de bay-windows, incorpora potentes e fraccionados contrafortes colgantes que imprimen ritmo e verticalidade ás fachadas, nunha solución que Soraluce non só vincula co influxo da exposición parisina "des Arts Décoratifs" de 1925 -fito da art déco-, senón tamén co expresionismo de Poelzig ${ }^{29}$.

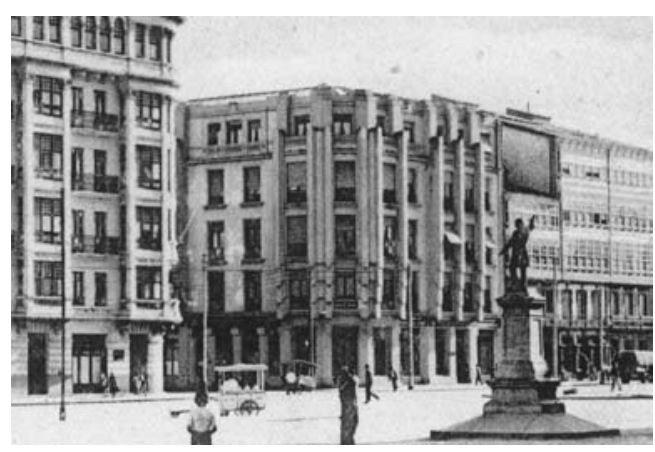

Fig. 10. Vista da Praza de Pontevedra da Coruña arredor de 1940. No centro, edificio da Sociedade de Seguros Mutuos, de Antonio Tenreiro 
Todos estes aspectos conforman o que por un breve tempo prometía ser a primeira gran arquitectura hoteleira da Coruña despois da tentativa do Gran Casino-Hotel; pero outra vez, e por razóns que, sen podermos precisalas, parecen imputables a unha mestura de indecisión política e dificultades económicas, os plans dilúense no esquecemento. A súa singularidade estaría, dende o punto de vista tipolóxico, no carácter ad hoc que comparte co proxecto de 1920, pero neste caso ao destino hoteleiro suma ese epíteto "de turismo", que delata o enfoque a unha clientela familiar adiñeirada, ociosa, inclinada a estadías prolongadas especialmente no verán, diferente en definitiva á aquela que adoita nutrir os hoteis "de viaxeiros" 30 . Dende o punto de vista construtivo, tamén como o Casino-Hotel, destacaría polas súas dimensións e previsible importancia no corazón dunha urbe de hoteis pequenos. E dende o punto de vista estilístico atópase ao final dunha tradición hoteleira profundamente ecléctica na que o tipo arquitectónico se liga reiteradamente á exuberancia historicista de raíz beaux-arts: o Hotel de Turismo constitúe, sen renunciar á invocación dun luxo palaciano e cosmopolita, un dos poucos deseños art déco con que Tenreiro e Estellés preparan o seu desembarco na estética moderna. Máis dunha década máis tarde, un hotel moi distinto, o Finisterre, acaba construíndose asomado ao mar no Parrote, non sen esquecer que o impulsa unha antiga aspiración: " ¡Un Hotel de turismo! Al fin, lo tendrá nuestra ciudad. No es un sueño ni una idea que vaga en la mente o queda limitada a unos planos $(\ldots)^{\prime \prime 31}$.

\section{A urbanización da praia de Santa Cristi- na. A utopía dun enclave de vacacións}

As particulares condicións xeográficas e urbanas da Coruña, a súa praia de Riazor-Orzán, o seu benigno clima e o seu animado ambiente estival, entre outros reclamos dos que presumía fronte ás principais cidades turísticas españolas, explican que se considerase urxente para o interese público dotar o centro da poboación dun "hotel de turismo". Pero o escenario tradicional do hotel turístico non é o corazón da cidade, onde o verdadeiro triunfador é o que antes aludimos como "hotel de viaxeiros": un establecemento que resulta inercialmente impregnado pola actividade política, social e económica que protagoniza a elite burguesa do sistema urbano. Grandes cidades como Londres demostran a influencia das infraestruturas do transporte na formación de núcleos hoteleiros, en especial polos numerosos aloxamentos que durante 0 século XIX xorden ao abeiro das estacións de tren; pero máis alá de viaxeiros cabe especificar que moitas veces falamos de viaxantes, axentes comerciais que levan unha vida ambulante por razóns profesionais e que representan un dos principais clientes dos hoteis urbanos ${ }^{32}$. Neste sentido, A Coruña non é unha excepción: malia a compatibilidade coa explotación turística, os Francia, Palace ou Atlantic son beneficiarios da histórica dimensión portuaria e capitalina da cidade, cuxo pulso se prolonga neles en forma de eventos políticos, tratos comerciais e celebracións da alta sociedade local.

Fronte a este panorama, o hotel turístico ou de vacacións -sen deixar de ser unha manifestación do sistema urbano- establécese tradicionalmente fóra da cidade na procura dunha valoración especial da natureza. Moitos representantes desta tradición líganse ao balneario, establecemento con fondo arraigo na historia europea que se revitaliza dende o século XVIII e que inicia en Galicia un notable crecemento arquitectónico a finais do XIX ${ }^{33}$. Se o balneario basea a súa razón de ser nos efectos medicinais atribuídos ás augas de determinados mananciais, usualmente combinadas cun ambiente propicio para a restauración da saúde, pronto xorden outras perspectivas que fan unha valoración máis xeral dos efectos curativos da natureza. Determinados enclaves rurais, forestais, montañosos ou costeiros, xeralmente accesibles en pouco tempo dende a cidade, subministran á burguesía o paréntese idóneo na súa vida cotiá, trocando a rutineira paisaxe urbana por escenarios extraordinarios na súa beleza salvaxe: trátase dos resorts, centros vacacionais con grande implantación dende cedo en Estados Unidos ${ }^{34}$. Máis alá da auga, o resort parte de considerar a paisaxe natural, combinada cun clima agradable, benéfica para o home, axeitada para a tranquilidade, o deleite e o descanso; pero sen renunciar a dotar ao hóspede das comodidades da cidade e dun marco privilexiado para cultivar as relacións sociais. 
Na liña do que os americanos chaman resort, o hotel de praia figura como un dos tipos máis comúns e concorridos entre os hoteis de vacacións. Non hai que esquecer que, aínda que a afluencia turística produza co tempo unha urbanización intensiva dos enclaves costeiros, a praia valórase, cando os primeiros hoteis comezan a tomar posicións ao seu carón, como un lugar cheo de virtudes naturais: comezando polos baños de mar -que supoñen unha equiparación directa cos balnearios tradicionais-, pasando polas calidades vivificantes da brisa e rematando por suposto coa recoñecida beleza da paisaxe mariña. Con estes ingredientes, non é raro que algunhas das figuras máis prestixiosas da hotelaría histórica europea correspondan con hoteis de praia, como é o caso do impresionante Gran Hotel de Scarborough, en Inglaterra (C. Brodrick, 1863-67).

Na altura de 1930, a praia de Santa Cristina do concello de Oleiros, limítrofe co da Coruña, aparece como herdeira destas consideracións. Areal amplo, abrigado e relativamente agreste, situado na embocadura da ría do Burgo, Santa Cristina ínzase nos días de verán de coruñeses ociosos que veñen de descubrir ao lado da casa un recuncho ideal onde tomar os baños de mar e de sol [fig. 11]. Alí encóntranse cun ambiente de singular cosmopolitismo, a dicir dun cronista, como "una especie de Lido transportado a esta punta del continente" ao que asisten reputados apelidos da zona ${ }^{35}$. As actividades ao aire libre triúnfan neste escenario onde, máis alá do baño, conviven a animada conversa, os xogos e os deportes, a exhibición do bronceado, o picnic e a terraza de bar, e mesmo o fascinante e novísimo espectáculo da aviación, ao establecerse sobre a area a pista de aterraxe local ${ }^{36}$. Ironicamente, os mesmos atributos que se lle recoñecen a esta paraxe implican un conflito e un problema que José Luís Bugallal manifesta en 1930 así:

He aquí una playa ártabra conocida. Casi, casi, la única, si se tienen en cuenta las condiciones escasamente favorables de Riazor. $Y$ con todo, a pesar de su amplitud, de su belleza, de su jocundidad, de su proximidad a la capital, Santa Cristina continúa siendo una playa primitiva, una playa inexplotada, una playa en el más desconsolador abandono (...) Me seduce Santa Cristina por lo que tiene de salvaje, de despreocupado,

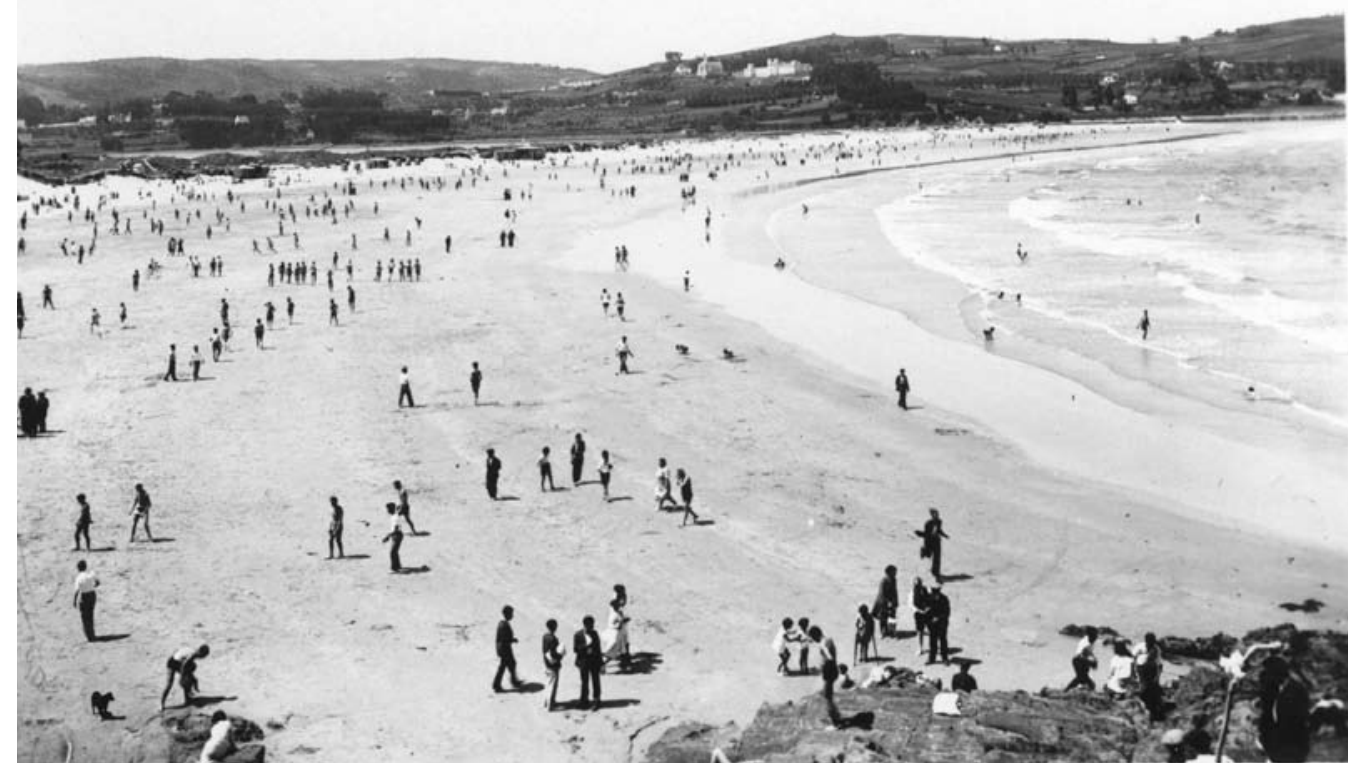

Fig. 11. Vista da praia de Santa Cristina arredor de 1930 
de rústico. Si un día el hormigón hollase estas dunas, la clientela de Santa Cristina emigraría a otra playa (...) Pero no obstante, reconozco, como el primero, la necesidad ineludible de convertir esta playa en el gran balneario que La Coruña precisa. Es ya cuestión de decoro ciudadano el poder presentar al forastero una playa moderna, dotada de todo género de comodidades (...) No puede estar de moda una playa que por faltarle lo más indispensable, hasta carece de una breve carretera de acceso. $^{37}$

Uns días antes destas palabras presentábase ao PNT, como xa vimos, unha proposta de hotel de turismo para A Coruña e ademais, xunto a ela, un proxecto "para reforma y embellecimiento de la Playa de Santa Cristina y terrenos limítrofes". O plano que se achega é seguramente o titulado "Anteproyecto de Urbanización de Perillo y de la Playa de Santa Cristina" [fig. 12], asinado en xaneiro de 1930 polos arquitectos Antonio Tenreiro e Peregrín Estellés e tamén, ao colaborar o exército, polo coronel de estado maior Joaquín Souto ${ }^{38}$. Os plans non se levaron a cabo polas súas enormes dimensións e custe, algo que xa se advirte dende o primeiro momento: "el proyecto de esta reforma es vastísimo y por su importancia económica inadecuado para realizar de una vez"; o propio presidente do PNT, preguntado en 1931 por esta cuestión, destaca os inconvenientes da situación arredada da praia e insinúa o aprazamento sine die de toda iniciativa ${ }^{39}$.

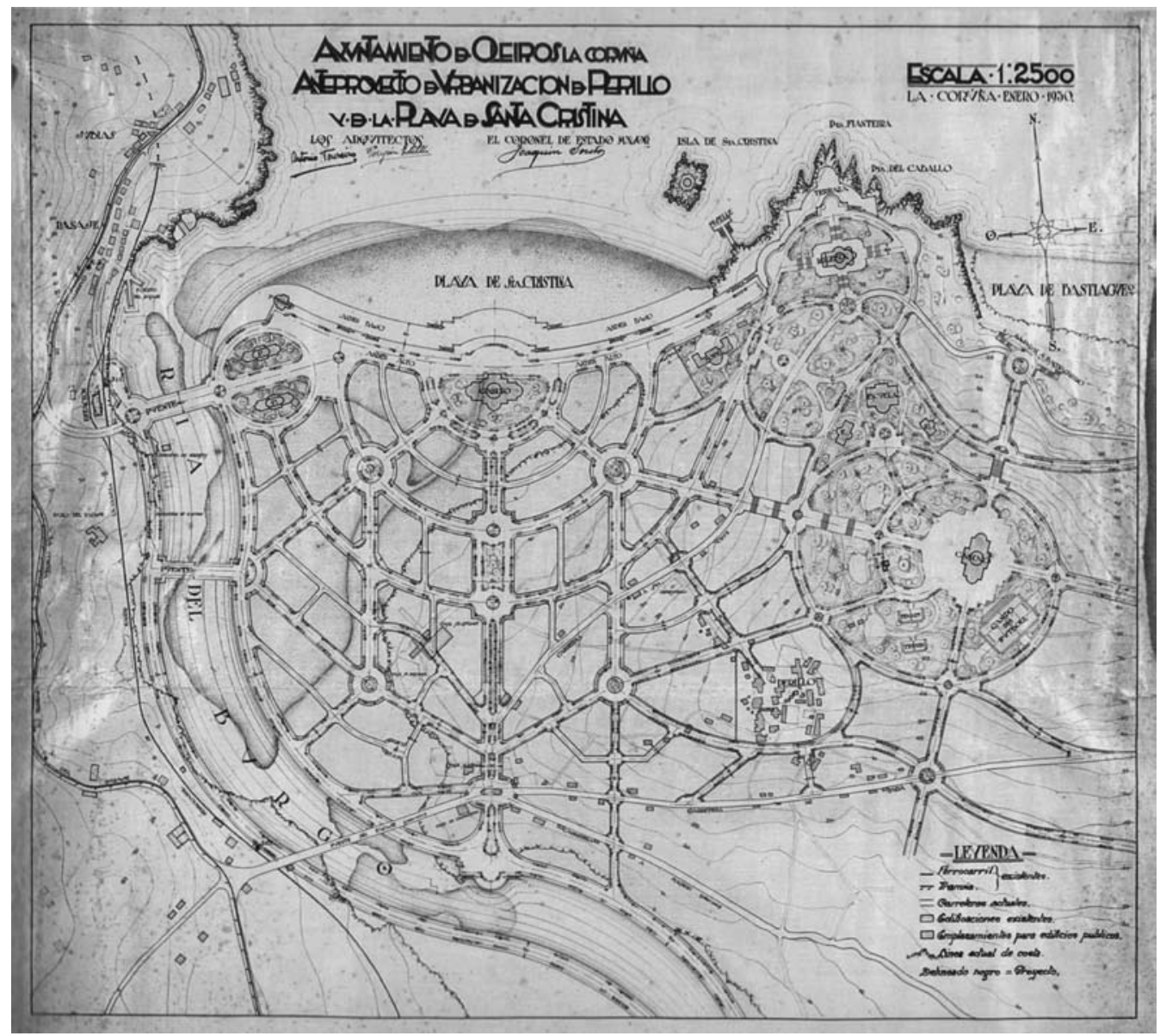

Fig. 12. Anteproxecto de urbanización de Perillo e a praia de Santa Cristina. Antonio Tenreiro e Peregrín Estellés, 1930. Colexio Oficial de Arquitectos de Galicia, delegación da Coruña (doado pola familia de A. Tenreiro) 
Os arquitectos afrontan unha xeografía ampla e desigual $\left(1,54 \mathrm{~km}^{2}\right)$, apenas edificada aparte do pequeno núcleo rural de Perillo, limitada no lado occidental e meridional pola ría do Burgo, ao norte pola propia praia e ao leste por unha lomba que remata na punta Fieiteira, tras da cal está a praia de Bastiagueiro. Planéase superpoñer ao territorio unha malla viaria regular, dominada por varias arterias abertas en abanico e facendo da medular unha avenida monumental. Diversos edificios de uso público ocupan os puntos estratéxicos. Os protagonistas son dous casinos situados respectivamente nos núcleos dos que parten as rúas principais: un centra a praia de Santa Cristina e outro coroa o punto máis elevado da lomba oriental, integrando o ámbito de Bastiagueiro no conxunto. Toda ela destinada a parques, esta lomba completa o seu perfil coa escola e a igrexa, mentres que o hotel se establece aos seus pés, lindando coa praia. Varios aneis semicirculares conectan as rúas radiais abrindo glorietas nas interseccións, formando así unha multitude de rueiros destinados ás residencias particulares do que prometía ser unha vasta urbanización de luxo. A grandilocuencia do proxecto complétase coas longas plataformas dos paseos da praia e da ría, que desfiguran a orografía orixinal segando o sistema dunar e aplicando grandes recheos de terra. Para mellorar as comunicacións coa Coruña, xa beneficiadas da inmediatez da liña do ferrocarril, prevense dúas novas pontes que, sumadas a outra existente, conforman unha espazosa rede de vomitorios converxente non obstante nun colo de botella na estrada das Xubias.

Dun xeito xenérico, están na memoria plans de urbanización intensiva de paraxes naturais como o de Vázquez-Gulías para a illa da Toxa (1904). Pero a nivel compositivo, o proxecto é herdeiro dunha visión escenográfica e xerarquizada das vías que ten moito de versallesca, cos seus enfáticos eixes de simetría e a súa disciplina xeométrica, aínda que matizada polas variacións coa liña curva. Elementos como a pautación radial foran xa ensaiados por Tenreiro na súa ci- dade satélite Concepción Arenal (1928-30) ${ }^{40}$. O seu principal referente estaría en Antonio Palacios, cuxo plan de Extensión e Reforma Interior de Vigo (1930-32) propón para a zona balnearia unha solución conceptualmente idéntica: unha composición das vías radial co eixe de simetría monumentalizado e unha posición escenográfica dos principais edificios. Neste sentido, Naya sinala a colaboración de Palacios no "anteproyecto de urbanización de la Playa de Santa Cristina y Hotel de Turismo"41. Por outra banda, o interese en dotar á viguesa praia de Samil dun hotel turístico colle forza tamén nestes anos, como explica Areal, aínda que os plans tampouco prosperan ${ }^{42}$.

Ao centrármonos no hotel, que é o que nos interesa, a información que obtemos do plano é escasa, alén de que se sitúa á carón da praia e de que a súa planta, cun pavillón central en ábsida e dúas alas curtas, non ten relación coa traza de Hotel de Turismo que vimos. Pero a memoria técnica dá algún dato máis: mentres o que está ao pé da praia se cataloga de "hotel de turistas", o casino que coroa o promontorio invoca sen dúbida vellas aspiracións ao denominarse "casino hotel" 43, integrando polo tanto unha dobre función enfatizada aquí por unha retórica arquitectura bifronte, perfilada cunha ábsida en cada extremo ao modo das basílicas romanas. Desta forma, advertimos que, antes que dar un papel secundario á función hoteleira, este proxecto destácaa por partida dobre e ademais outórgalle unha posición de dominio sobre o resto da composición. Se ben son dous exemplares apenas esbozados, o seu encaixe ilustra perfectamente dúas concepcións non tan distantes que practicamente vimos conxugadas no proxecto para A Coruña: a dun hotel de praia destinado a estadías vacacionais e a dun hotel urbano de clase alta no que se confunden viaxeiros e burguesía local. Ao cabo, o plan para Santa Cristina promete sumar as máis excelentes calidades como cidade e como balneario, sen descontar ese carácter "esimismado" do que falaba Leboreiro Amaro. 


\section{NOTAS}

1 O presente traballo realizouse co apoio dunha bolsa do Programa de FPU do Ministerio de Educación, así como no marco do proxecto de investigación La visión del artista. Ciudad y arquitectura en Galicia desde la Edad Media hasta la irrupción de la fotografía (HAR2011-24968), financiado polo Ministerio de Economía. Departamento de Historia da Arte da Universidade de Santiago de Compostela.

${ }^{2}$ DÍAZ LÓPEZ, J. D. Fondas, hospedaxes e hoteis da cidade da Coruña. A definición dunha tipoloxía arquitectónica (17791950). Dir. Alfredo Vigo Trasancos. Tese de licenciatura sen publicar. Universidade de Santiago, dep. Historia da Arte, 2011 Pode consultarse unha copia en http://bit.ly/HotelC

${ }^{3}$ VIGO TRASANCOS, A. "La Coruña, 1886-1935, perfil histórico de una ciudad en los comienzos de nuestro siglo", en Vida en la ciudad: La Coruña: fines del XIX, comienzos del XX (exposición). A Coruña: Concello, D.L. 1992, p. 18: "los 'locos veinte' (...) se erigieron en edad de oro del verano coruñés".

${ }^{4}$ DÍAZ LÓPEZ, op. cit., pp. 156-159.

${ }^{5}$ Os primeiros que coñecemos son os hoteis Europa e Universal de Vigo [ibid., p. 157., a partir dos datos de AREAL ALONSO, P. A. A Arquitectura dos hoteis de Vigo no cambio de século (1850-1950). Santiago de Compostela: Xunta de Galicia, Dir. Xeral para o Turismo, D.L. 1998, pp. 60-62 e 72-77].

6 "Estado de la hacienda municipal", en El Orzán, 8-V1930; "La construcción de un Gran Hotel", en El Orzán, 15-X1930; "Proyectos de turismo", en El Orzán, 12-IV-1931.

7 PELLEJERO MARTínEZ, C. "La política turística en España. Una perspectiva histórica", en Las nuevas formas del turismo (Joaquín Aurioles Martín, coord.). Caja Rural Intermediterránea. Cajamar, 2004, pp. 268-271.

8 Ibid., pp. 272-273.

9 "El Patronato Nacional de Turismo", en La Voz de Galicia, 15-X-1930: "El propósito del Patronato es la construcción de tres grandes hoteles: Cádiz, La Coruña y Vigo, como puertos, aparte el de Santiago por la condición especial de aquella c[i]udad, en el aspecto histórico, artístico y monumental".

${ }^{10}$ AREAL ALONSO, op. cit., pp. 160-169.

${ }^{11}$ O Hotel Compostela inaugúrase o 23 de agosto de 1930 coas achegas do Patronato Nacional do Turismo, mais este organismo non ten que ver coa súa promoción inicial, que data de 1926. Os plans do Patronato para un hotel en Santiago son mencionados meses despois desta inauguración. Cfr. "Los actos de ayer en Santiago", en La Voz de Galicia, 24-VIII-1930; "El Hotel Compostela...", en El Orzán, 24-VIII-1930; "El Patronato Nacional de Turismo", en La Voz de Galicia, 15-X-1930.

12 "La construcción de un Gran Hotel", en El Orzán, 15X-1930; "El Patronato Nacional de Turismo", en La Voz de Galicia, 15-X-1930.

13 "Proyectos de turismo", en El Orzán, 12-IV-1931. Como puidemos ver, as principais áreas de distribución dos aloxamentos coruñeses nesta época correspondían coa fronte portuaria -especialmente na zona do Obelisco-, coa Rúa Nova, coa rúa dos Olmos e co longo eixe de San Andrés (DÍAZ LÓPEZ, op. cit., fig. 1b).
${ }^{14}$ Son respectivamente as sociedades Parisiana, constituída en 1920, e Hijos de José María Rodríguez, da que temos noticia en 1925.

${ }^{15}$ AMC, Fondo Tenreiro, C-197(1-9) e C-62.

${ }^{16}$ No citado artigo de La Voz de Galicia do 15-X-1930 dise que "parece que son tres los técnicos que en su ejecución intervendrán".

${ }^{17}$ PÉREZ SÁNCHEZ, Y. El Balneario de Mondariz, la creación de un lugar (1873-1931). Tese de doutoramento. Universidade de Santiago de Compostela, Facultade de Xeografía e Historia, Departamento de Historia da Arte, 2005, cap. II.3.2, esp. pp. 343, 368 e 392.

18 Proxectado por Isaiah Rogers en 1827. Vid. PEVSNER, N. Historia de las tipologías arquitectónicas. Barcelona: Gustavo Gili, 1980, p. 211.

${ }^{19}$ Sobre o deseño orixinal do Atlantic improvisouse unha compartimentación para dar cabida ás habitacións.

20 AMC, Concello da Coruña, obras particulares, C-491(30)

${ }^{21}$ O primeiro hotel que nos consta con ascensor na Coruña é o Hotel de Francia en 1912 e pouco despois o Palace en 1916 (DÍAZ LÓPEZ, op. cit., pp. 79 e 87).

22 O Atlantic, coa súa terraza superior, desenvolvera xa este concepto (ibid., p. 105).

${ }^{23}$ Nótese que, en calquera dos casos, non se acadan as 190 habitacións que se proxectaran para o Gran Casino-Hotel en 1920, o que resalta a ambición daqueloutro proxecto.

${ }^{24}$ A concepción dunha planta baixa dedicada exclusivamente ás dependencias de servizo vémola sobre todo nos hoteis Atlantic e Embajador (ibid., pp. 102-103 e 146).

${ }^{25}$ O Finisterre e probablemente tamén o Embajador optan anos despois por esta solución lóxica de levar os tratamentos da roupa (lavado, secado, pasado de ferro, etc.) a un lugar ventilado (ibid., pp. 146-147).

${ }^{26}$ Tomamos en consideración as noticias xa referidas de El Orzán (8-V-1930; 15-X-1930; 12-IV-1931) e de La Voz de Galicia (15-X-1930). Os datos descritivos do proxecto aparecen soamente en El Orzán do 15-X-1930.

${ }^{27}$ A denominación á inglesa introdúcena na Coruña o Palace Hotel e o Atlantic Hotel.

${ }^{28}$ Proxectado en 1929 para a coruñesa Praza de Pontevedra; hoxe desaparecido.

${ }^{29}$ AGRASAR QUIROGA, F. (ed.). Antonio Tenreiro. 18931972. A Coruña: Colexio Oficial de Arquitectos de Galicia, 2007, p. 67.

${ }^{30}$ Esta distinción hotel de turismo/hotel de viaxeiros é contemporánea da época que tratamos. Vid. por exemplo "Los Bandos de la Alcaldía...", en La Prensa (diario de Tenerife), 18-VIII-1929.

31 "Un gran hotel", en Hoja oficial del lunes, 17-V-1943.

32 Ademais dos viaxantes, médicos e sanadores itinerantes son hóspedes moi comúns dos hoteis nas primeiras décadas do século $X X$, como ben testemuña a prensa de ámbito galego. Este tipo de clientela é a esencia do que se deu en chamar "hotel comercial", que arredor de 1820 xa ofrece exem- 
plos en Estados Unidos (SANDOVAL-STRAUSZ, A. K. Hotel: an American history. Yale University Press, 2007, p. 82).

33 LEBOREIRO AMARO, Ma A. El balneario. La ciudad ensimismada. Vigo: Colexio Oficial de Arquitectos de Galicia, 1994 , p. 48 e ss.

${ }^{34}$ SANDOVAL-STRAUSZ, op. cit., p. 87 e ss.

35 "De sociedad. En Santa Cristina", en El Orzán, 24-IX1927.

${ }^{36}$ Vid. por exemplo en El Orzán: "Ayer marcharon otros cuatro aparatos", 7-VII-1926; "El aviador Ansaldo...", 9-IX1930; "Llegada de un aeroplano", 6-VIII-1931.

37 "Las playas ártabras", en El Orzán, 28-X-1930.

${ }^{38}$ Orixinal no COAG, sede da Coruña.
${ }^{39} \mathrm{Vid}$. nota 6.

${ }^{40}$ AGRASAR QUIROGA (ed.), op. cit., p. 66.

${ }^{41}$ NAYA PÉREZ, J. Noticia histórica de las galerías coruñesas y relación de arquitectos de La Coruña desde que se creó el cargo hasta el presente. A Coruña: Instituto "José Cornide", 1965, p. 75. A alusión á urbanización de Santa Cristina e o Hotel de Turismo resulta confusa, por canto queda demostrado que son dous proxectos diferentes. Non obstante, hai que ter en conta que na urbanización da praia inclúese un hotel deste tipo.

${ }^{42}$ AREAL ALONSO, op. cit., pp. 164-165. Manuel Gómez Román concreta o primeiro proxecto coñecido, de 1935.

${ }^{43}$ AMC, Fondo Tenreiro, C-10(11), fols. 4-5. 